\title{
HUBUNGAN PANJANG BOBOT, PERBANDINGAN JENIS KELAMIN, DAN TINGKAT KEMATANGAN GONAD TUNA MATA BESAR (Thunnus obesus) DI PERAIRAN LAUT BANDA
}

\author{
Budi Nugraha") dan Siti Mardlijah")
}

\begin{abstract}
ABSTRAK
Penelitian dilakukan terhadap tuna mata besar hasil tangkapan kapal tuna long line yang beroperasi di perairan Laut Banda. Aspek biologi yang diteliti meliputi hubungan panjang bobot, perbandingan jenis kelamin, ukuran pertama kali matang gonad, dan tingkat kematangan gonad pada bulan Oktober sampai dengan Desember 2002. Dari hasil analisis hubungan panjang bobot diketahui bahwa pola pertumbuhan tuna mata besar di perairan Laut Banda bersifat allometrik negatif. Perbandingan jenis kelamin jantan dan betina adalah 1,96:1, berdasarkan pada hasil uji Chi-Square menunjukkan bahwa rasio ikan jantan dan betina pada periode penelitian ini tidak seimbang di mana jumlah jantan 2 kali betina. Ikan betina matang gonad pada ukuran lebih kecil dibandingkan dengan ikan jantan. Pemijahan tuna mata besar di perairan Laut Banda terjadi pada bulan Desember.
\end{abstract}

KATA KUNCI: biologi, tuna mata besar, perairan Laut Banda

ABSTRACT: $\quad$ L-W relationship, sex ratio, and maturity of big eye tuna (Thunnus obesus) in the Banda Sea. By: Budi Nugraha and Siti Mardlijah

Research on big eye tuna in Banda Sea waters covered L-W relationship, sex ratio, length at first maturity, and maturity stages of the gonad was conducted in October to December 2002. The fish examinated in this study were collected from the catch of tuna long line. Results show that growth pattem of big eye tuna was negative allometric. Sex ratio of the male and female was 1,96:1. Based on Chi-Square test, it shows that the number of the male was almost twice of the female. The length of maturity of the female was smaller than that of the male. Big eye tuna in Banda Sea waters was presumably spawned in December.

\section{KEYWORDS: biology, big eye tuna, Banda Sea waters}

\section{PENDAHULUAN}

Tuna mata besar (Thunnus obesus) atau lebih dikenal dengan big eye tuna adalah salah satu anggota famili Scombridae dan merupakan salah satu komoditi ekspor perikanan tuna yang paling utama di Indonesia selain madidihang (Thunnus albacares) dan tuna sirip biru selatan (Thunnus maccoyii). Ekspor tuna mata besar pada umumnya dalam bentuk segar dan beku. Berdasarkan pada data Dinas Perikanan Propinsi Bali dan PPSJ Muara Baru dalam Proctor et al., (2003) dikatakan bahwa pada tahun 2002 tuna yang diekspor dalam bentuk segar dan beku sekitar $18.011,5$ ton dari Bali dan 17.471 ton dari Muara Baru dengan negara tujuan Jepang, Amerika, Inggris, dan lainlain.

Tuna mata besar tersebar di seluruh perairan di dunia baik di perairan tropis maupun sub tropis yang meliputi perairan Samudera Atlantik, Samudera Hindia, dan Samudera Pasifik. Tuna mata besar mempunyai panjang cagak maksimum lebih dari $200 \mathrm{~cm}$, dan pada umumnya $180 \mathrm{~cm}$. Di perairan Pasifik bagian barat dan Samudera Hindia panjang cagak tuna mata besar dewasa mencapai 100 sampai dengan $130 \mathrm{~cm}$, dan di perairan Pasifik bagian tengah sekitar $130 \mathrm{~cm}$ (Collette \& Nauen, 1983).

Sumber daya tuna, terutama tuna mata besar di perairan Laut Banda mempunyai kualitas yang cukup tinggi dibandingkan dengan tuna mata besar di perairan lain di Indonesia (Sidik, Komunikasi Langsung, 2002). Tujuan dari penelitian ini adalah untuk mengetahui hubungan panjang bobot, rasio kelamin, dan tingkat kematangan gonad tuna mata besar dari perairan Laut Banda. Diharapkan tulisan ini menjadi bahan dan informasi awal untuk penelitian selanjutnya mengenai ikan tersebut.

\section{BAHAN DAN METODE}

Contoh ikan yang dianalisis 80 ekor tuna mata besar berasal dari hasil tangkapan kapal tuna long

\footnotetext{
Peneliti pada Balai Riset Perikanan Laut, Muara Baru-Jakarta
} 
line KM. Samodera 37 milik PT. Perikanan Samodera Besar. Ikan tersebut merupakan hasil tangkapan pada bulan Oktober sampai dengan Desember 2002. Pengamatan biologi yang dilakukan meliputi hubungan panjang bobot, perbandingan jenis kelamin, ukuran pertama kali matang gonad, dan tingkat kematangan gonad.

Untuk mengetahui hubungan panjang bobot digunakan rumus Bal \& Rao (1984), yaitu:

$$
W=a L^{b}
$$

di mana:

$$
\begin{aligned}
& \mathrm{W}=\text { berat ikan }(\mathrm{g}) \\
& \mathrm{L}=\text { panjang ikan }(\mathrm{cm}) \\
& \mathrm{a} \text { dan } \mathrm{b}=\text { konstanta }
\end{aligned}
$$

Pengujian perbandingan jenis kelamin dilakukan dengan uji Chi-Square (Sugiyono, 2004):

$$
X^{2}=\sum_{i=1}^{k} \frac{(f o-f n)^{2}}{f n}
$$

di mana:

$$
\begin{aligned}
& x^{2}=\text { Chi Square } \\
& \text { fo }=\text { frekuensi yang diobservasi } \\
& \text { fn }=\text { frekuensi yang diharapkan }
\end{aligned}
$$

Dalam menganalisis ukuran pertama kali matang gonad digunakan metode SpearmanKarber (Udupa, 1986) sebagai berikut:

$$
m=X k+X / 2-\left(X x \sum p i\right)
$$

di mana:

$m=$ logaritma panjang pertama kali matang gonad

$$
\begin{aligned}
\mathrm{Xk}= & \text { logaritma nilai tengah kelas panjang di } \\
& \text { mana semua ikan matang gonad } 100 \% \\
& \text { (tingkat } 4 \text { ) } \\
\mathrm{X}= & \text { selisih logaritma nilai tengah } \\
\mathrm{pi}= & \text { proporsi ikan yang matang gonad pada } \\
& \text { kelas panjang ke-i }
\end{aligned}
$$

Sehingga rata-rata ukuran pertama kali matang gonad adalah:

$$
M=\operatorname{antilog}(m)
$$

Sedangkan untuk menghitung batas kepercayaan $95 \%$ (confidence limit) menggunakan rumus:

$$
C L=\operatorname{anti} \log \left(m \pm 1,96 \sqrt{X^{2} x \sum p i}\right)
$$

Penentuan tingkat kematangan gonad tuna mata besar mengacu pada kriteria menurut Kesteven (Bagenal \& Braum, 1968 dalam Effendie, 1997) yang dibagi dalam 9 tingkat yaitu:

1. Dara: Organ seksual sangat kecil berdekatan di bawah tulang punggung. Testes dan ovarium transparan, dari tidak berwarna sampai dengan berwarna abu-abu. Butir-butir telur tidak terlihat dengan mata.

2. Dara Berkembang: Testes dan ovarium jernih, abu-abu kemerahan. Panjang setengah atau lebih sedikit dari panjang rongga bawah. Butir telur satu per satu dapat terlihat dengan kaca pembesar.

3. Perkembangan I: Testes dan ovarium bentuk bulat telur, berwarna kemerah-merahan dengan pembuluh kapiler. Gonad mengisi kira-kira setengah ruang ke bagian bawah. Telur dapat terlihat seperti serbuk putih.

4. Perkembangan II: Testes berwarna putih kemerah-merahan. Untuk jantan, tidak ada sperma kalau bagian perut ditekan. Ovarium berwarna orange kemerah-merahan. Telur jelas dapat dibedakan, bentuk bulat telur. Ovarium mengisi kira-kira 2 per 3 ruang bawah.

5. Bunting: Organ seksual mengisi ruang bawah: Testes berwarna putih, keluar tetesan sperma kalau ditekan perut. Telur bentuk bulat, jernih dan masak.

6. Mijah: Telur dan sperma keluar dengan sedikit tekanan ke perut. Sebagian besar telur berwarna jernih dengan beberapa yang berbentuk bulat telur tinggal di dalam ovarium.

7. Mijah atau salin: Gonad belum kosong sama sekali. Tidak ada telur yang bulat telur.

8. Salin: Testes dan ovarium kosong dan berwarna merah. Beberapa telur sedang dalam keadaan dihisap kembali.

9. Pulih salin: Testes dan ovarium berwarna jernih, abu-abu sampai dengan merah.

\section{HASIL DAN BAHASAN}

\section{Hubungan Panjang Bobot}

Dari hasil analisis regresi diperoleh persamaan hubungan panjang bobot $W=0,0003 \quad L^{2,4703}$, $\mathrm{R}^{2}=0,9194$ dengan nilai $\mathrm{b}=2,4703$ untuk ikan jantan; dan $W=0,0002 L^{2,5671}, R^{2}=0,8067$ dengan nilai $b=2,5671$ untuk ikan betina (Gambar 1). Hasil pengujian nilai $b$ yang diperoleh terhadap nilai 3 pada taraf 95 dan $99 \%$ baik ikan jantan maupun betina menunjukkan kurang dari $3(b<3)$.

Pertumbuhan ikan di suatu perairan banyak dipengaruhi oleh faktor lingkungan antara lain ukuran makanan yang dimakan, jumlah ikan di 

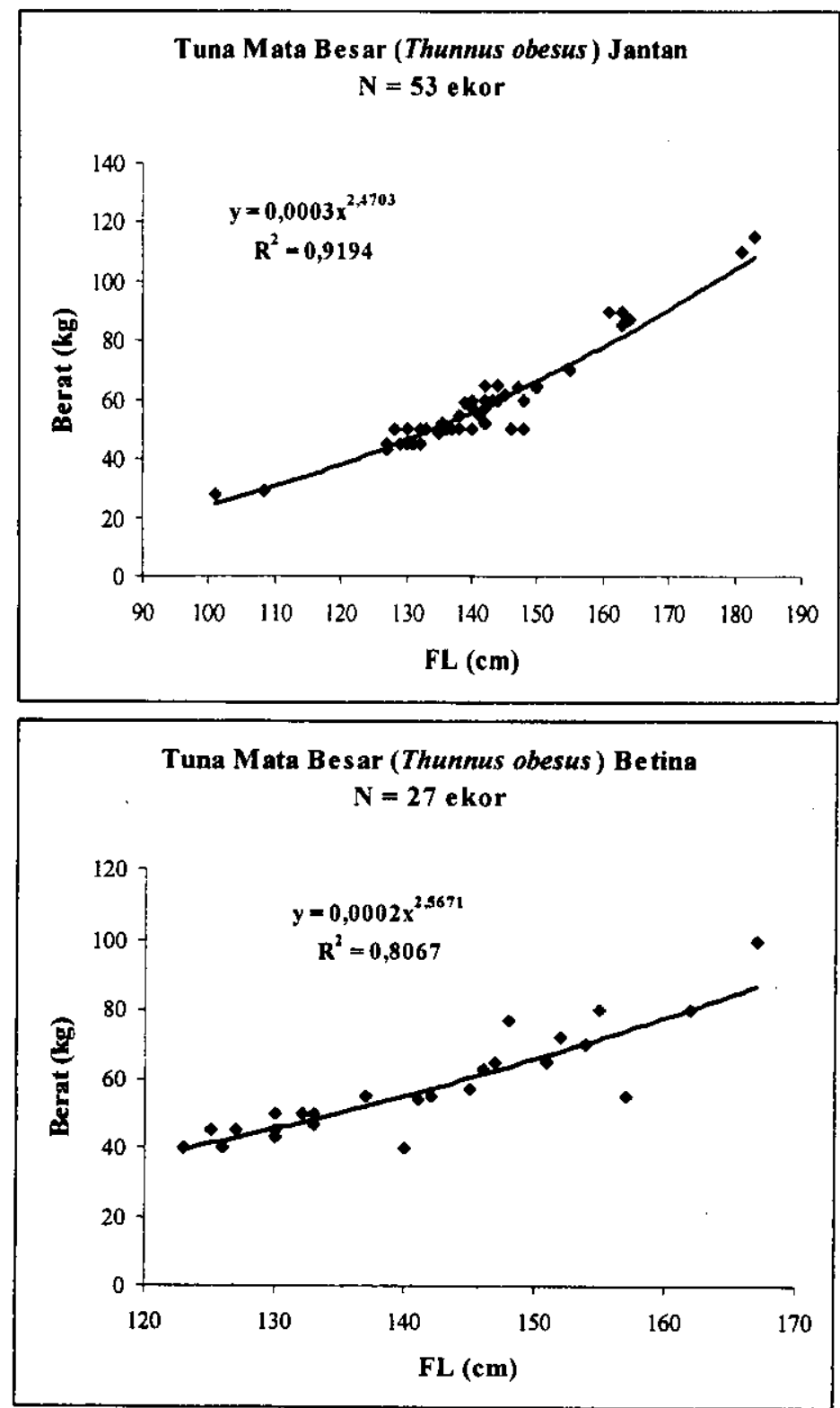

Gambar 1. Hubungan panjang bobot tuna mata besar jantan dan betina yang tertangkap di perairan

Laut Banda.

Figure 1. Lenght weight relationships of male and female big eye tuna caught in Banda Sea waters.

perairan tersebut, jenis makanan yang dimakan, kondisi oseanografi perairan (suhu, oksigen, dan lain-lain) dan kondisi ikan (umur, keturunan, dan genetik) (Sukimin et al., 2002). Pertumbuhan tuna mata besar di perairan Laut Banda tidak sama dengan pertumbuhan tuna mata besar di perairan Samudera Pasifik bagian barat. Sun et al., (2001) mengatakan bahwa tuna mata besar di perairan Samudera Pasifik bagian barat hasil tangkapan tuna long line bersifat allometrik positif. Berdasarkan pada informasi tersebut, dapat dikatakan bahwa tuna mata besar di perairan Laut Banda mempunyai ukuran lebih panjang dibandingkan tuna mata besar di perairan Samudera Pasifik bagian barat pada bobot yang sama.

\section{Perbandingan Jenis Kelamin}

Perbandingan jenis kelamin (sex ratio) adalah suatu angka yang menunjukkan perbandingan jumlah individu jantan dan betina dalam suatu populasi. Variasi dalam perbandingan kelamin sering terjadi dikarenakan 3 faktor yaitu perbedaan tingkah laku seks, kondisi lingkungan, dan penangkapan (Bal \& Rao, 1984). Pendugaan rasio 
jenis kelamin sangat dibutuhkan sebagai bahan pertimbangan dalam produksi, rekruitmen, dan konservasi sumber daya ikan tersebut (Sukimin et al., 2002).

Dari pengamatan terhadap 80 ekor tuna mata besar diperoleh hasil bahwa 53 ekor berkelamin jantan dan 27 ekor berkelamin betina. Hasil ini menunjukkan perbandingan kelamin tuna mata besar adalah 1,96:1. Berdasarkan pada hasil uji Chi-Square secara keseluruhan diperoleh bahwa hasil sangat berbeda nyata di mana $\chi$ hitung $>\chi$ tabel $\quad\left(\chi^{2}=8,45 ; \quad \chi^{2} \quad\right.$ tabel $_{(0,05)}=3,481 ; \quad \chi^{2}$ tabel $\left._{(0,01)}=6,635\right)$, dengan demikian dapat disimpulkan bahwa perbandingan jenis kelamin jantan dan betina dalam keadaan tidak seimbang.

\section{Ukuran Pertama Kali Matang Gonad}

Untuk menghitung ukuran ikan pertama kali matang gonad diasumsikan bahwa ikan mulai matang gonad pada tingkat kematangan gonad 4 . Kematangan gonad ikan pertama kali diduga pada tingkat kematangan gonad 4 di mana testes berwarna putih kemerah-merahan. Ovarium berwarna orange kemerah-merahan dan mengisi kira-kira 2 per 3 ruang bawah. Bentuk telur yang bulat dapat dibedakan dengan jelas. Berdasarkan pada analisis dengan metode Spearman-Karber diperoleh dugaan rata-rata ukuran pertama kali matang gonad untuk ikan jantan adalah 146,1 cm dengan batas kepercayaan antara 140,5 sampai dengan 151,9 cm (Lampiran 1) dan untuk ikan betina $133,5 \mathrm{~cm}$ dengan batas kepercayaan 129,1 sampai dengan 137,9 cm (Lampiran 2). Dari hasil analisis tersebut terlihat bahwa ikan betina mulai matang gonad pada ukuran lebih kecil dibandingkan dengan ikan jantan, yang berarti bahwa ikan betina lebih cepat matang gonad daripada ikan jantan.

Ukuran pertama kali matang gonad tuna mata besar di perairan Laut Banda mempunyai ukuran yang lebih besar dibandingkan dengan tuna mata besar di perairan lain. Kikawa (1953) yang dikutip oleh Miyabe (1994) mengatakan bahwa ukuran minimum pertama kali matang gonad (minimum size at first maturity) tuna mata besar Pasifik antara 91 sampai dengan $100 \mathrm{~cm}$. Calkins (1980) mengatakan bahwa, ukuran pertama kali matang gonad tuna mata besar di Samudera Pasifik dapat mencapai 100 sampai dengan $130 \mathrm{~cm}$ ketika mereka berumur sekitar 3 tahun. Menurut Udupa (1986), ukuran pertama kali matang gonad setiap ikan sangat bervariasi baik itu di antara jenis ikan maupun dalam jenis ikan itu. Dengan demikian, individu yang berasal dari 1 kelas umur ataupun dari kelas panjang yang sama tidak selalu harus mencapai panjang pertama kali matang gonad pada ukuran yang sama.

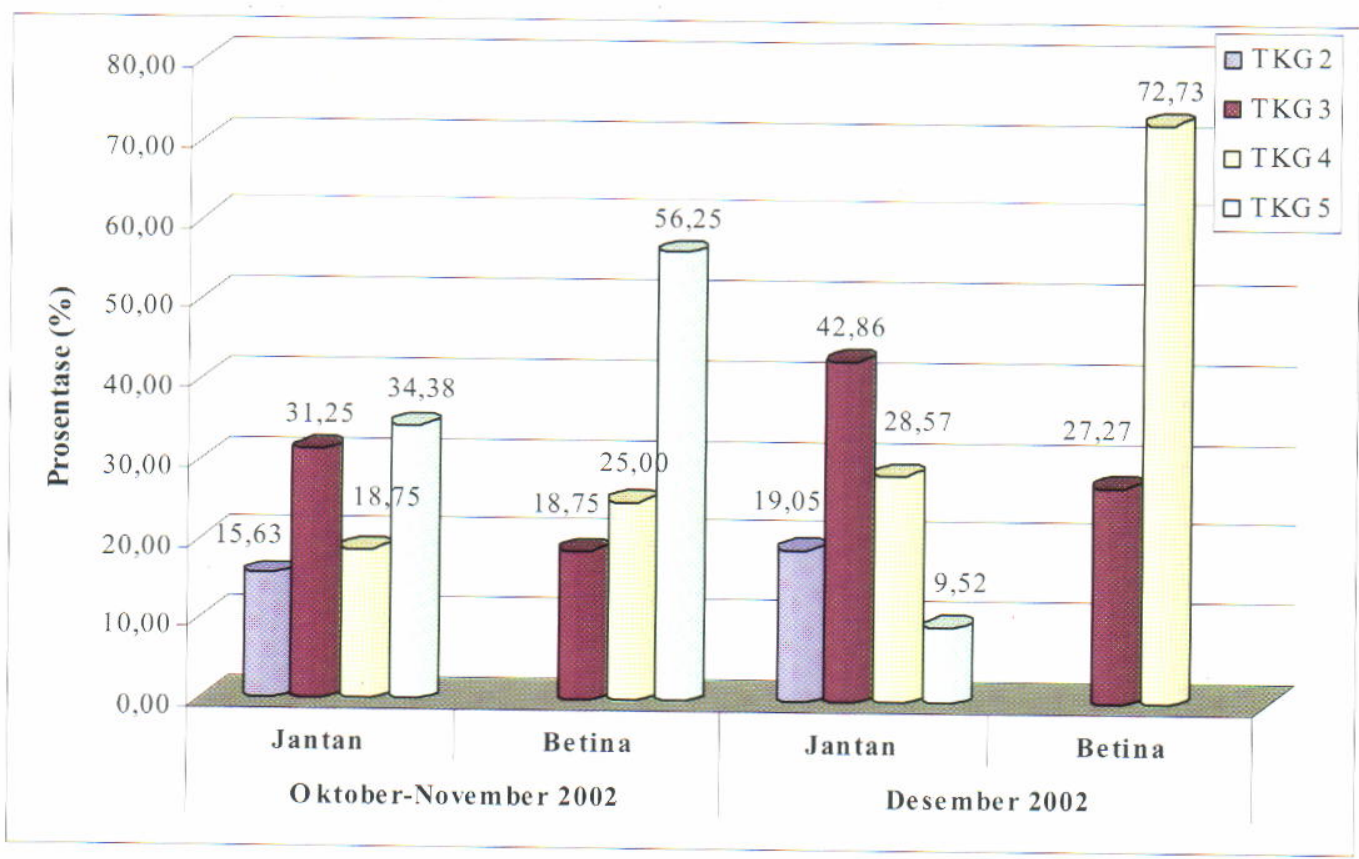

Gambar 2. Persentase tingkat kematangan gonad tuna mata besar jantan dan betina hasil tangkapan tuna long line pada bulan Oktober sampai dengan Desember 2002 di perairan Laut Banda.

Figure 2. Percentage of maturity stages of the male and female gonads of big eye tuna caught by tuna long line in October to December 2002 in Banda Sea waters. 


\section{Tingkat Kematangan Gonad}

Tingkat kematangan gonad adalah tahap tertentu perkembangan gonad sebelum dan sesudah ikan memijah (Effendie, 1979). Penentuan tingkat kematangan gonad sangat penting dilakukan, karena sangat berguna untuk mengetahui perbandingan antara gonad yang masak dengan stok yang ada di perairan, ukuran pemijahan, musim pemijahan, dan lama pemijahan dalam suatu siklus (Sukimin et al., 2002). Penentuan tingkat kematangan gonad dapat dilakukan dengan 2 cara yaitu secara morfologis (visual) dan secara histologis. Untuk penelitian di perairan Laut Banda penentuan tingkat kematangan gonad dilakukan secara morfologis (visual).

Dari pengamatan secara morfologis (visual) diperoleh 4 tingkat yaitu tingkat kematangan gonad 2, 3, 4, dan 5. Pada Gambar 2 terlihat bahwa pada bulan Oktober sampai dengan Nopember 2002 ikan jantan dan betina didominasi oleh tingkat kematangan gonad 5 , sedangkan pada bulan Desember 2002 ikan jantan didominasi oleh tingkat kematangan gonad 3 dan ikan betina didominasi oleh tingkat kematangan gonad 4. tingkat kematangan gonad 5 ikan jantan pada bulan Desember 2002 mulai berkurang, bahkan untuk ikan betina sudah tidak ada lagi. Hal ini, menunjukkan bahwa pada bulan tersebut sudah banyak ikan jantan dan betina yang sudah memijah (spawned). Dari hasil tersebut dapat diduga bahwa perairan Laut Banda merupakan salah satu daerah pemijahan tuna mata besar. Menurut Collette \& Nauen, (1983), di perairan Pasifik sebelah timur pemijahan tuna mata besar terjadi antara lintang $10^{\circ} \mathrm{LU}$ dan $10^{\circ} \mathrm{LS}$ sepanjang tahun, dengan puncak pada bulan April sampai dengan September di belahan bumi utara dan antara bulan Januari dan Maret di belahan bumi selatan. Nishikawa et al. (1985) juga mengatakan bahwa tuna mata besar memijah sepanjang tahun dan di sekitar daerah khatulistiwa di Samudera Atlantik, Samudera Hindia, dan Samudera Pasifik.

Berdasarkan pada data yang diperoleh menunjukkan bahwa ikan jantan yang berukuran lebih kecil dari ukuran pertama kali matang gonad adalah $69,8 \%$ yang didominasi oleh tingkat kematangan gonad $3(29,73 \%)$ (11 ekor) dan betina $51,9 \%$ yang didominasi oleh tingkat kematangan gonad $3(42,86 \%)$ (6 ekor).

\section{KESIMPULAN}

1. Pola pertumbuhan tuna mata besar jantan dan betina bersifat allometrik negatif.

2. Perbandingan kelamin ikan jantan dan betina adalah 1,96:1 dan dalam keadaan tidak seimbang.

3. Ukuran pertama kali matang gonad untuk ikan jantan adalah $146,1 \mathrm{~cm}$ dan untuk ikan betina $433,5 \mathrm{~cm}$.

\section{DAFTAR PUSTAKA}

Bal, D. V. \& K. V. Rao. 1984. Marine fisheries. Tata Mc. Graw-Hill Publishing Company Limited. New Delhi. p 5-24.

Calkins, T. 1980. Synopsis of biological data on the big eye tuna, Thunnus obesus (Lowe, 1839), in the Pacific Ocean. Inter-Am. Trop. Tuna Comm. Spec. Rep. 2. 213-259.

Collette, B. B. \& C. E. Nauen. 1983. FAO Species catalogue. Vol.2. Scombrids of the World. An Annotated and Illustrated Catalogue of Tunas, Mackerels, Bonitos, and Related Species Known to Date. FAO Fish. Synop. (125) Vol.2. FAO. Rome. 137p.

Effendie, M. I. 1979. Metoda biologi perikanan. Yayasan Dewi Sri. Bogor. 112 hal.

Effendie, M. I. 1997. Biologi perikanan. Yayasan Pustaka Nusatama. Yogyakarta. 163 hal.

Miyabe, N. 1994. A Review of the biology and fisheries for big eye tuna, Thunnus obesus, in the Pacific Ocean in Proceedings of the First FAO Expert Consultation on Interactions of Pacific Tuna Fisheries. Vol.2.

Nishikawa, Y., M. Honma, S. Ueyanagi, \& S. Kikawa. 1985. Average distribution of larvae of oceanic species of scombroid fishes. 19561981. Far Seas Fish. Res. Lab. S ser. 12.

Proctor, C. H., I. G. S. Merta, Fedi Sondita, Ronny Wahju, Tim Davis, Jhon Gunn, \& Retno Andamari. 2003. A review of.Indonesia's Indian Ocean tuna fisheries. ACIAR Project $\mathrm{FIS} / 2001 / 079$. 
Sugiyono. 2004. Statistik non parametris untuk penelitian. Penerbit CV. Alfabeta. Bandung. 158 hal.

Sun, L. C., C. L. Huang, \& S. Z. Yeh. 2001. Age and growth of the big eye tuna, Thunnus obesus, in the Western Pacific Ocean in http://fishbull.noaa.gov/993/sun.pdf.
Sukimin, S., Isdrajat S., \& Yon Vitner. 2002. Petunjuk praktikum biologi perikanan. Fakultas Perikanan dan IImu Kelautan. Institut Pertanian Bogor. Bogor.

Udupa, K. S. 1986. Statistical method of estimating the size at first maturity in fishes. Fishbyte. 4 (2): 8-10. ICLARM. Metro Manila. 


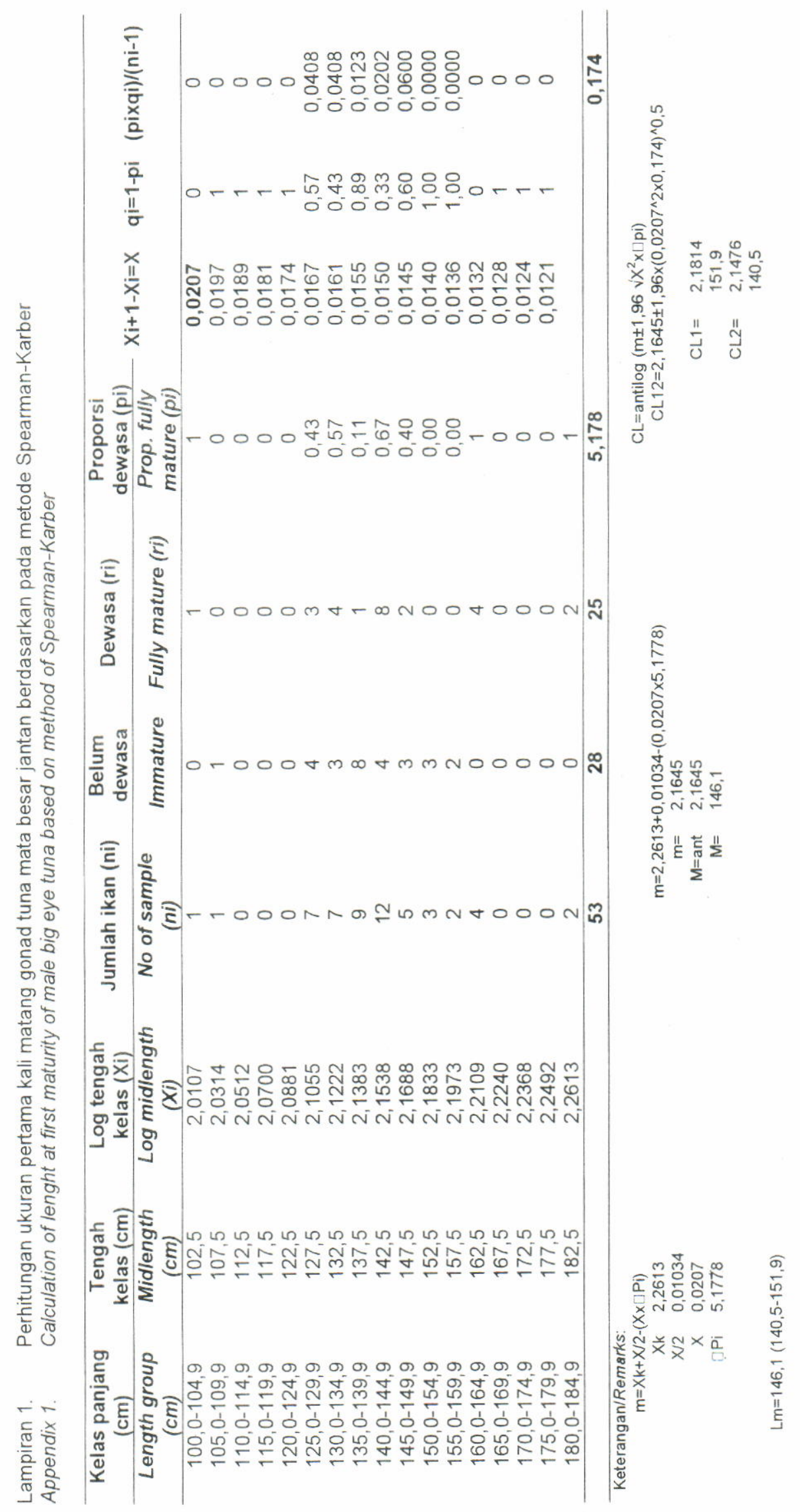




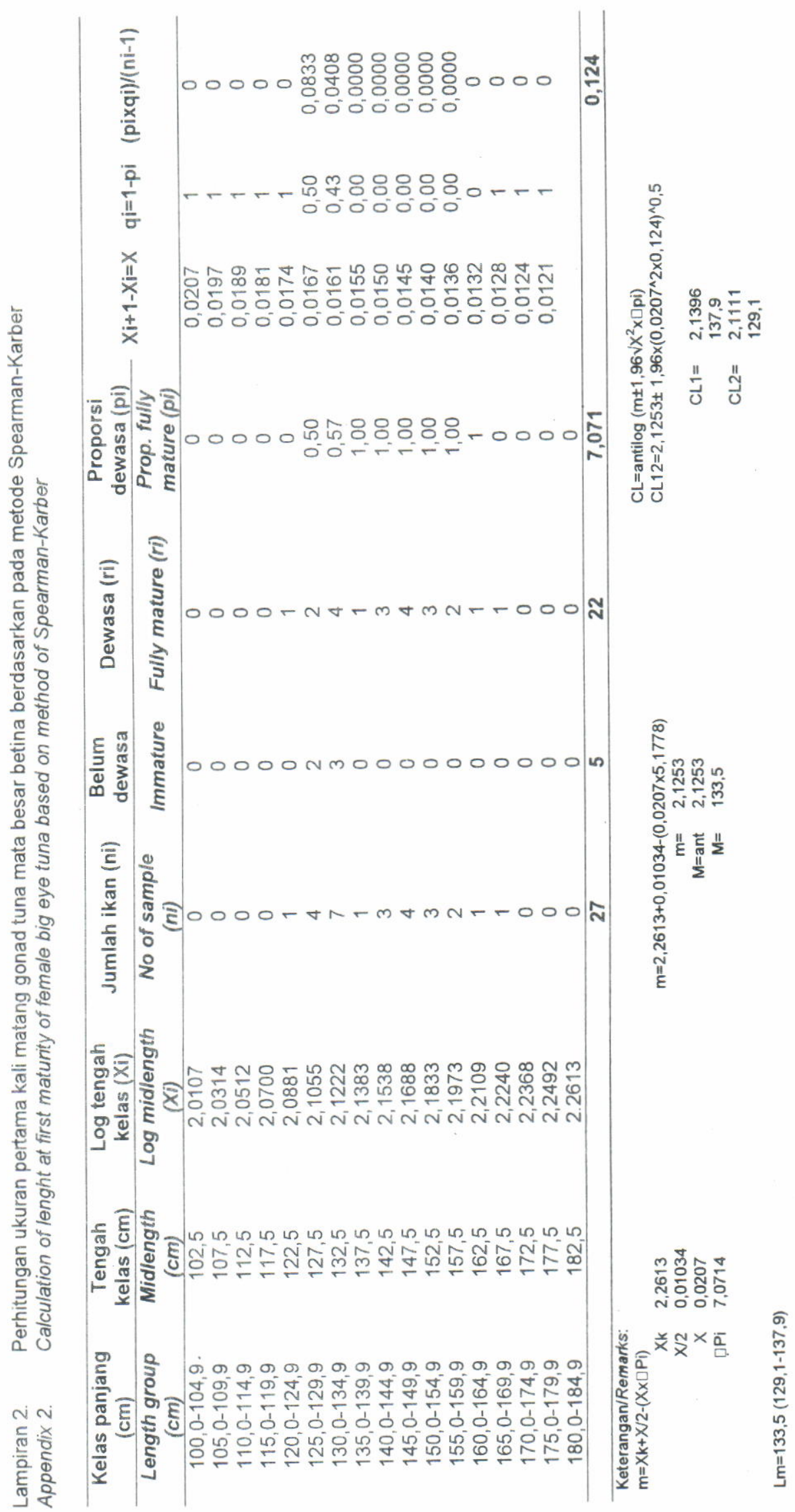

